\title{
Fatal typhoid intestinal perforation in post tubal ligation death with an alleged medical negligence: a rare case report
}

\author{
Pankaj Suresh Ghormade ${ }^{1 *}$, Ajay Narmadaprasad Keoliya ${ }^{2}$
}

\begin{abstract}
${ }^{1}$ Department of Forensic Medicine and Toxicology, All India Institute of Medical Sciences, Raipur, Chhattisgarh, India
${ }^{2}$ Department of Forensic Medicine and Toxicology, Government Medical College, Nagpur, Maharashtra, India
\end{abstract}

Received: 07 December 2017

Accepted: 08 January 2018

\section{*Correspondence:}

Dr. Pankaj Suresh Ghormade,

E-mail: pankajforensic@gmail.com

Copyright: (c) the author(s), publisher and licensee Medip Academy. This is an open-access article distributed under the terms of the Creative Commons Attribution Non-Commercial License, which permits unrestricted non-commercial use, distribution, and reproduction in any medium, provided the original work is properly cited.

\begin{abstract}
Worldwide tubal sterilization is commonly used procedure for family planning method. Tubal ligation by minilaparotomy under local anaesthesia is most commonly used method of female sterilization in India. The death rate after tubal sterilizations is 72/100000 for all procedures and mainly due to general anaesthesia or vascular injuries. Iatrogenic injury to bowel can occur in minilaparotomy tubal ligations if there are dense adhesions of intestines or history of previous surgery. In the present case of interval post tubal ligation by minilaparotomy, fatal ileal perforation due to typhoid fever was detected on autopsy which was confirmed after complete histological and lab investigations. Atypical complications of typhoid fever were also noted. In developing countries, typhoid fever is the leading cause of non-traumatic free perforation of intestine and its incidence ranges from $0.9 \%$ to $39 \%$, with a high mortality rate. This is rare case of an alleged medical negligence after surgery; in which deciding factor was cause of intestinal perforation i.e. iatrogenic or natural and it posed a difficult challenge.
\end{abstract}

Keywords: Iatrogenic, Ileal, Minilaparotomy, Natural, Perforation, Tubal ligation, Typhoid fever

\section{INTRODUCTION}

Worldwide tubal sterilization is commonly used procedure for family planning method. In India according to National Family Health Survey-4 (2015-16), 36\% of currently married women in the age group 15-49 years were sterilized which accounted for $66 \%$ of all the contraception use, making it a leading method of contraception. ${ }^{1}$

In female sterilization operation, tubal access for tubal occlusion can be achieved by following surgical methods laparoscopy, minilaparotomy, laparotomy or trancervically via Hysteroscopy and tubal occlusion can be done by resection of a segment (tubectomy) or by blocking of fallopian tubes by use of rings or clips. Tubal ligation by Minilaparotomy under local anaesthesia is safe and cost-effective procedure and most commonly used method of female sterilization in India. ${ }^{2}$ The death rate after tubal sterilizations is $72 / 100000$ for all procedures and mainly due to general anesthesia or vascular injuries.

Intra-operative complication includes visceral (bowel, bladder, uterus) injury, vascular injury and complications of anaesthesia and seen in less than 1 out of 100 procedures. ${ }^{2}$ Iatrogenic injury to bowel can occur in Minilaparotomy tubal ligations if there are dense adhesions of intestines or history of previous surgery. ${ }^{3}$

In the present case of death after interval post tubal ligation, we have found ileal perforation with peritonitis due to typhoid fever on autopsy.

This is a rare case presentation, where differentiating cause of intestinal perforation i.e. traumatic or natural 
was deciding factor in backdrop of surgical procedure with allegation of medical negligence.

\section{CASE REPORT}

32 years old female patient after proper Pre-Anaesthetic Checkup (PAC) fitness was admitted for elective interval tubectomy operation at private nursing home and operated by Gynaecologist, under local anaesthesia with sedation. Abdomen was opened by Minilaparotomy method and bilateral tubal ligation was carried out by Modified Pomroy's technique. Then, she had developed fever and abdominal pain on $2^{\text {rd }}$ post-operative (PO) day followed by vomiting and progressive abdominal distention. On $4^{\text {th }} \mathrm{PO}$ day, she had one episode of massive hematemesis leading to hypotension and despite of treatment patient died. Clinical investigations revealed, about $400 \mathrm{ml}$ of free fluid on USG and purulent fluid on ascitic tapping. As relatives made allegation of medical negligence and cause of death was unclear, requisition for medico legal autopsy was given by investigating police authority in this case. Dead body was sent for medico legal autopsy in Department of Forensic Medicine at tertiary care hospital. Post-mortem interval was 8 hours in this case.

On post mortem examinations following findings were noted:

\section{External examination}

Deceased had BMI $18.1 \mathrm{~kg} / \mathrm{m}^{2}$, generalized pallor noted. Rigor mortis was well marked in whole body and postmortem lividity fixed. Abdomen was distended and surgical stitched wound present over suprapubic region of abdomen in midline, on removing stitches; vertically placed minilaparotomy incised wound noted of size $3 \mathrm{~cm}$.

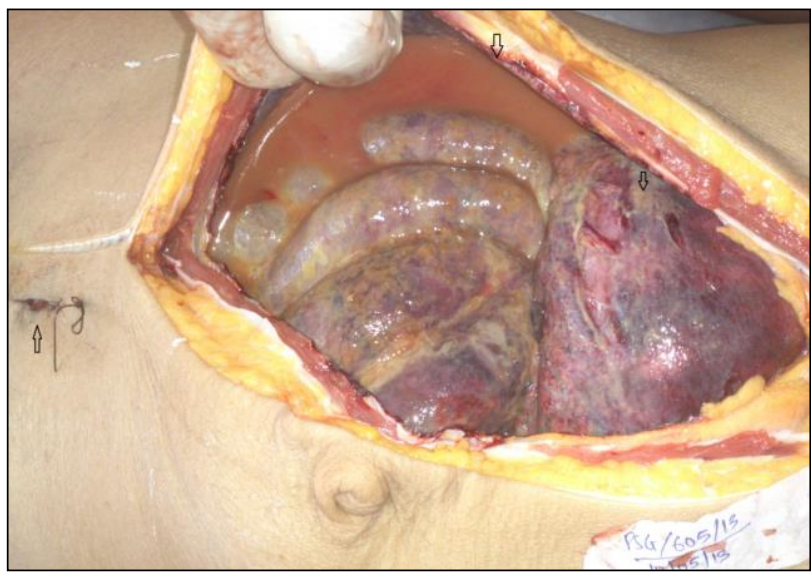

Figure 1: Findings of intra-abdominal sepsis with necro-inflammatory changes.

\section{Internal examination}

Each pleural cavity contains about $300 \mathrm{ml}$ reddish fluid, patchy consolidation noted in lungs, congestion and sub capsular pus flecks was present in liver and enlarged spleen weighing $230 \mathrm{gm}$. Peritoneal cavity contained about 2 litres of seropurulent fluid and showed findings of intraabdominal sepsis due to diffuse acute peritonitis. Discoloration due to necro-inflammatory changes was seen in abdominal wall, stomach and small intestines. Peritoneum showed thickening and fibrous adhesions at places (Figure1).

Stomach wall depicts multiple gastric erosions along with exudative pus-filled spots at places (Figure 2).

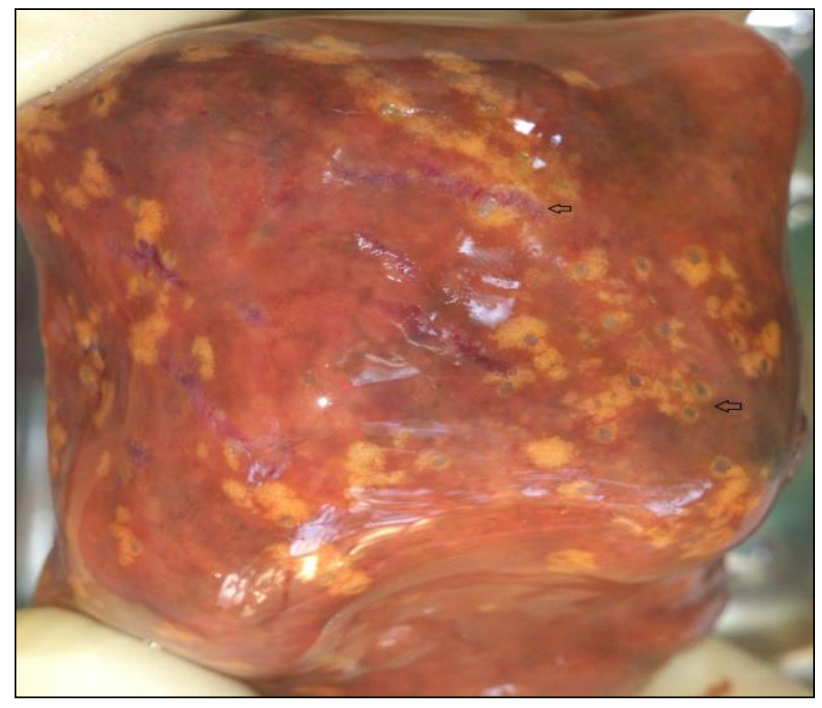

Figure 2: Findings in stomach: erosions and pus-filled exudates.

Full thickness perforation of size $1.5 \mathrm{~cm} \times 0.8 \mathrm{~cm}$ present in terminal portion of Ileum over anti mesenteric border situated $41 \mathrm{~cm}$ above the ileocecal junction; necroinflammatory changes were present around margins and base of perforation (Figure 3).

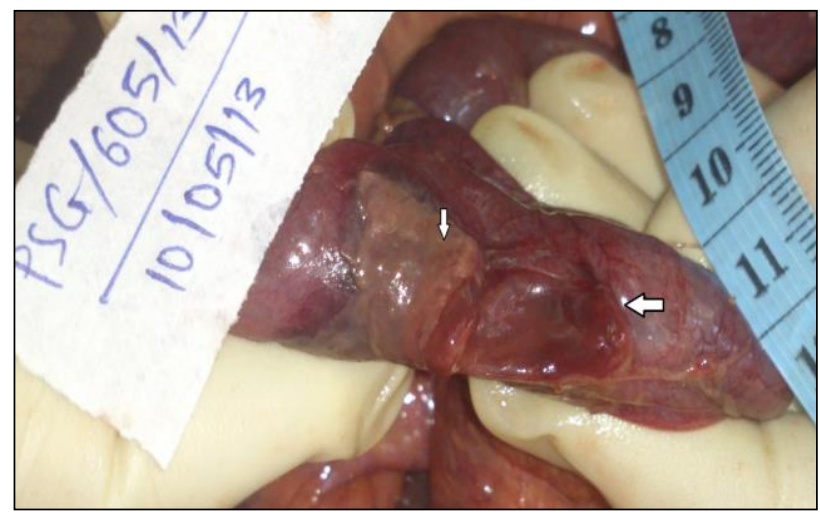

Figure 3: Ileal perforation with necro-inflammatory changes at base and margins.

Uterus, adnexa and ovaries shows patchy necroinflammatory changes. Intact suture was seen at tubal ligation sites (Figure 4). There was no evidence of duodenal ulceration. All other organs were normal. 


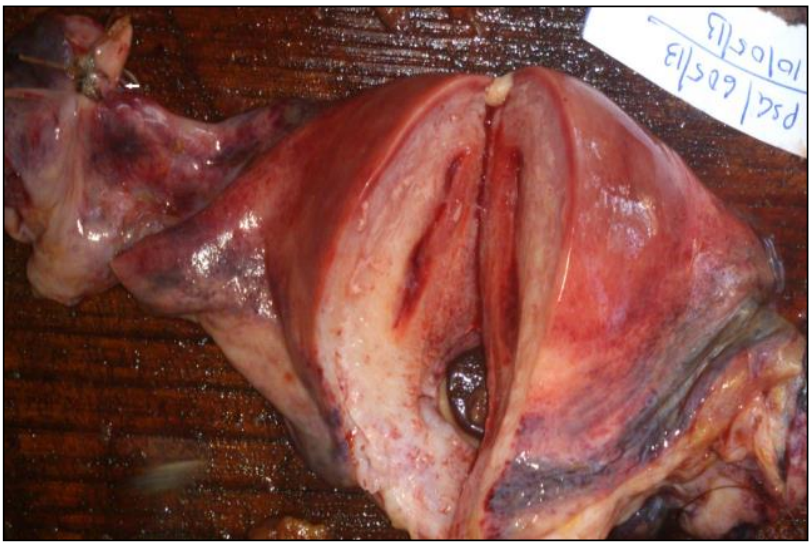

Figure 4: Tubal ligation site and findings in uterus.

Bacteriology from the pleural and intra-abdominal fluid showed mixed bacterial growth and no unusual pathogens. Bone marrow aspirate was collected from iliac crest, cultured on MacConkey's agar and it showed growth for S. typhi. On histological examination, sections from ileal perforation sites and its base revealed marked lymphocytic infiltration along with necrosis which suggestive of typhoid ileitis (Figure 5).

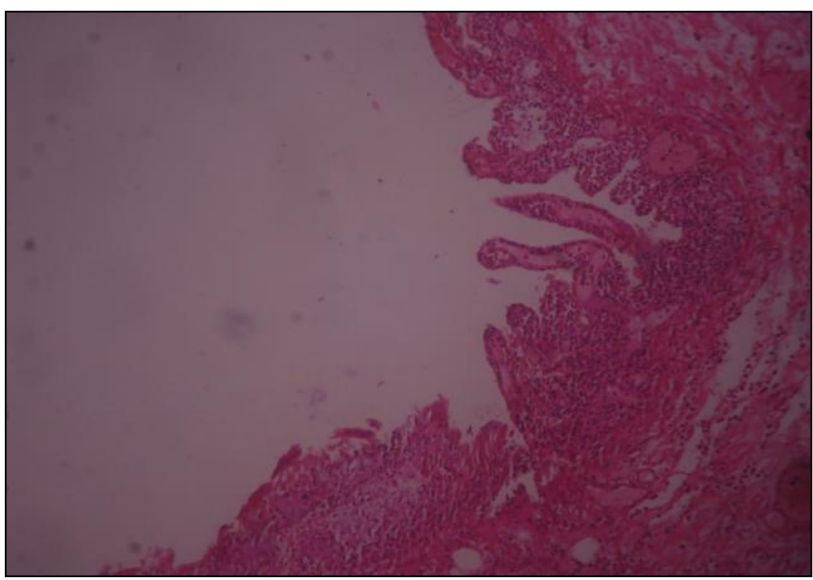

Figure 5: Diffuse lymhocytic infiltration at site of ileal perforation (H\&E 40X).

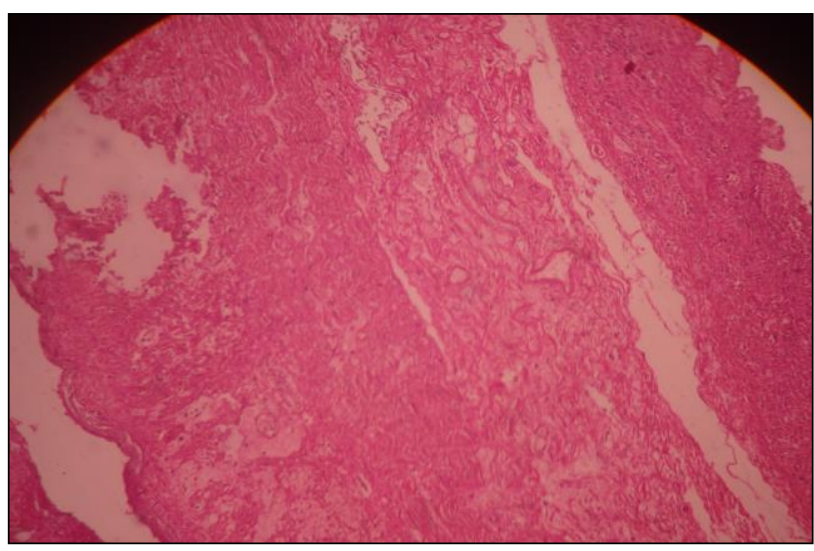

Figure 6: Diffuse lymphocytic infiltration in stomach (H\&E 40 X)
Stomach mucosa shows denudation and marked lymphocytic infiltrations extending up to serosal layer and marked necrosis (Figure 6).

In addition, complications like bilateral interstitial pneumonitis, liver abscess and abdominal wall necrosis were also noted. After considering all investigation reports, final autopsy diagnosis of septicaemia associated with acute peritonitis due to ileal perforation secondary to typhoid fever was given in this case.

\section{DISCUSSION}

In developing countries, typhoid fever is the leading cause of non-traumatic free perforation of intestine. ${ }^{4}$ Its incidence ranges from $0.9 \%$ to $39 \%$, with a mortality rate which remains very high. ${ }^{5}$ These causes are extremely rare in West where, Crohns disease, foreign bodies, perforated diverticula and radiation enteritis are important causes. $^{6}$ In enteric fever, bacteria become localized in ileal Peyer's patches causing hyperplasia of its lymphoid follicles and subsequent bacteraemia which spreads to phagocytic cells of liver, spleen and mesenteric lymph node.

Hyperplastic lymphoid follicles develop swelling and ulceration that can progress to capillary thrombosis and subsequent necrosis in $2^{\text {nd }}$ week. These ulcerations are always located on the antimesenteric border of the intestine and may perforate, usually in $3^{\text {rd }}$ week of disease. The gut in typhoid fever is edematous and friable (especially last $60 \mathrm{~cm}$ owing to high concentration of payers patches). There may be one or several perforations and many other impending perforations. ${ }^{7}$ Eggleston et al found typhoid perforations involving antimesenteric border of bowel where they appear as punched out holes and in contrast to other type of perforation, omental migration to perforated area does not occur. ${ }^{8}$ In gastrointestinal tuberculosis the most common site of involvement is the ileocecal region and terminal ileum and morphologically; the lesions are classified into ulcerative and ulcero-hypertrophic varieties. Confluent granulomas and presence of caseation necrosis is important histological criterion for diagnosis of intestinal tuberculosis. ${ }^{6}$

In cases of traumatic intestinal perforation following changes are seen, non-coagulative cell necrosis, more severe in muscle coat than the mucosa, a rapid and abdunt capillary ingrowth with white cell infiltration, rapid fibrin deposition at the injury site followed by fibroblastic proliferation and reconstruction of the injured muscle coat by 96 hours. ${ }^{9}$

In the present case, confirmatory bacteriological diagnosis of typhoid fever was obtained on bone marrow culture, which has supported histological diagnosis of enteric ileitis leading to ileal perforation. Hence, gross and histological findings seen at ileal perforation site were helpful in excluding other causes of perforation. 
Similarly, atypical complications of enteric fever like liver abscess, splenic enlargement and Pneumonitis were also present in this case. However; we noticed diffuse involvement of stomach as described above as complication of enteric fever after excluding other differential conditions. And such involvement of stomach in enteric fever is not mentioned in literature. This also explains underlying cause for bout of severe hematemesis as a complication of gastric abscess and erosions in pt. prior to her death.

Bowel injury is known complication of minilaparotomy and laparoscopy tubectomy female sterilization operation, and considering the reason for medico legal autopsy in our case; it was extremely important to diagnose the exact cause of intestinal perforation. ${ }^{3}$ Deceased was shown to be fit for surgery and PAC documents do not reveal any significant clinical history. However, on autopsy we noticed findings of severe intra-abdominal sepsis due to ileal perforation and atypical complications which were unlikely due to operative iatrogenic trauma and more likely due to spontaneous free perforation because of natural disease. Hence, autopsy was meticulously done with all necessary investigations that helped us to arrive at confirmatory diagnosis of enteric fever. In the present case, tubectomy procedure seems to be just incidental and is not responsible for aggravation of infection as it is relatively minor procedure and require limited abdominal access. Intestinal perforations mostly occur in $3^{\text {rd }}$ week of enteric fever, hence clinical diagnosis should have been suspected while taking history during PAC with proper lab investigations.

\section{CONCLUSION}

Iatrogenic intestinal perforation is not infrequent in abdominal surgical procedures; hence, it is important for autopsy surgeon to consider all common differential diagnoses before framing final diagnosis as such incidences may involve litigations for alleged medical negligence. This case highlights importance of meticulous autopsy and use of appropriate diagnostic techniques so that confirmatory scientific diagnosis can be given to investigating authorities for proper administration of justice. Similarly, clinicians especially in developing countries should be aware of such remote possibilities and be more vigilant while eliciting clinical history and symptoms in patient.
Funding: No funding sources

Conflict of interest: None declared

Ethical approval: Not required

\section{REFERENCES}

1. International Institute for Population Sciences (IIPS) 2016. National Family Health Survey (NFHS-4), 2015-16: India, Mumbai, IIPS. 2016:1-8.

2. Malhotra N, Puri R, Malhotra J. Tubes and ovaries. In: Malhotra N, eds. Operative obstetrics and gynecology, $2^{\text {nd }}$ ed. New Delhi: Jaypee Brothers Medical Publishers; 2014:455-60.

3. Cisse CT, Kerby K, Cisse ML, Diallo D, Faye EO, Moreira PM, et al. Complications of tubal sterilization by minilaparotomy under local anaesthesia. Dakar Med. 1997;42:96-8.

4. Yusuf NW, Iqbal S, Sarfraz R, Sohail SK, Imran M. Spectrum of pathologies in cases of intestinal obstruction and perforation based on histopathological examination of resected intestineReport from a third world country. Pak J Med Sci. 2014;30:373-9.

5. Atamanalp SS, Aydinli B, Ozturk G, Oren D, Basoglu M, Yildirgan MI. Typhoid intestinal perforations: twenty-six-year experience. World J Surg. 2007;31:1883-8.

6. Wani RA, Fazl PQ, Bhat NA, Wani MA, Bhat TH, Farzana F. Nontraumatic terminal ileal perforation. World J Emerg Surg. 2006;24:1-7.

7. Huckstep RL. Recent advances in the surgery of typhoid fever. Ann R Coll Surg Engl. 1960;26:20730.

8. Eggleston FC, Santoshi B, Singh CM. Typhoid perforation of bowel. Experiences in 78 cases. Ann Surg. 1979;190(1):31-5.

9. Soderstrom RM. Histologic changes associated with electrosurgical injury. J Minim Invasive Gynecol. 2013;20(3):299-300.

Cite this article as: Ghormade PS, Keoliya AN. Fatal typhoid intestinal perforation in post tubal ligation death with an alleged medical negligence: a rare case report. Int J Reprod Contracept Obstet Gynecol 2018;7:755-8. 